\title{
Building-centred community development as a method to promote social, environmental, and economic sustainability
}

\author{
A. Floros Phelps, C. Torres, D. Riley \& M. Horman \\ Department of Architectural Engineering, \\ The Pennsylvania State University, PA, USA
}

\begin{abstract}
Current community development programs in the United States and other countries consist primarily of planning and zoning regulations that focus on economic and population growth. In general, these measures have not resulted in the development of sustainable communities. This paper describes an effort to focus on a building-centred community development process. Building-centred community development utilizes the architecture, systems engineering, and materials that make up buildings as a strategy to promote socially, environmentally, and economically sustainable communities. The development of this solution is based on a five-year evolution of experimentation and analysis by the American Indian Housing Initiative at The Pennsylvania State University, and through application on the Northern Cheyenne reservation in Montana, USA. The design and construction of two prototype homes for two different communities are then presented as case studies for this project, including the utilization of an international design competition, the Solar Decathlon, as a vehicle for dissemination. The results of this research are presented including how building-centred community design affords the opportunity for economic development within a community related to: 1) The manufacture of building materials and systems; 2) Construction of homes and community buildings; and 3) Further research, development, and outreach.
\end{abstract}

Keywords: sustainable design, housing, community development, buildings, environmental capital, social capital, construction. 


\section{Introduction}

Traditional community development models have focused primarily on economic growth and increasing populations as a measure of success. These models have endorsed expanding labour forces, increased retail and wholesale commerce, more widespread and intense land development, higher population densities, and overall increased levels of financial activity [1]. The unintended consequences of these models have led to many of the social pathologies that result in lower quality of life, including urban and suburban sprawl, traffic, loss of community-specific architectural style, greater separation between income and race groups, environmental deterioration, and loss of agricultural land and wilderness. One limitation of these traditional models is that they only considered short-term economic growth instead of sustained long-term holistic growth. In the last 20 years, these problems have compelled some communities to consider more sustainable development strategies.

In 1987, the United Nation's World Commission on Environment and Development Report "Our Common Future" first formally defined the concept of sustainable development as "development that meets the needs if the present without compromising the ability of future generations to meet their own needs" [2]. In 1992, the United Nations Earth Summit held in Rio de Janeiro, Brazil resulted in the creation of Agenda 21 which set up the necessary policies and a plan to ensure the world's sustainable development for the $21^{\text {st }}$ century based on 27 principles which integrate political, economic, social, legal, and environmental aspects of sustainable development $[3,4]$.

Recent social reform movements, such as the New Urbanism, have moved away from the traditional economic model for community development to embrace a more holistic and sustainable approach. The New Urbanism Movement promotes community development that integrates social, economic, and environmental design to reduce sprawl and separation by race or income and preserve the environment, agricultural lands, wilderness, and society's built heritage [5]. Similarly, the Smart Growth program advocates that economic growth decisions should be explicitly linked to the quality of life [6]. As Hall [7] points out:

"Community design is the art of making sustainable living places that both thrive and adapt to people's needs for shelter, livelihood, commerce, recreation, and social order .... for too long communities have mistaken "aggregation" for "community" and "curb appeal" for "sense of place".

In sustainable community development circles, there is little debate regarding whether growth is good. As environmental architect William McDonough has remarked "Growth is good, ask a tree". The more important question is what type of growth should communities be promoting?

This paper presents a concept for development that considers the collective economic, environmental, and social value that exists within a community. This concept, referred to as building-centred community development, uses the design and construction of buildings as a catalyst for providing a sustainable means of increasing the overall value within a community. 


\section{Building centred community development}

Buildings are essential components of a community. In addition to providing shelter, safety, and allowing for increased productivity, buildings also embody our culture. The built environment creates a "sense of place" and connects people with the past while also leaving a legacy for the future [8]. Buildings also required significant investment of finances and resources both for the initial construction and over the lifespan of the building. In 2005, the construction industry accounted for $\$ 611$ billion dollars, or roughly $5 \%$ of the U.S. gross domestic product [9]. Table 1 illustrates the environmental impact of buildings as a percentage of the annual totals for the United States.

Table 1: Environmental impacts of buildings, percentage of U.S. annual impact: compiled from Levin, H., "Systemic Evaluation and Assessment of Building Environmental Performance" 1997 [10].

\begin{tabular}{|l|c|}
\hline Building Resource Use & $\begin{array}{c}\text { Percentage } \\
\text { of Total }\end{array}$ \\
\hline Energy Use & $42 \%$ \\
\hline Atmospheric Emissions & $40 \%$ \\
\hline Raw Material Use & $30 \%$ \\
\hline Solid Waste & $25 \%$ \\
\hline Water Use & $25 \%$ \\
\hline Water Effluents & $20 \%$ \\
\hline Other Releases & $13 \%$ \\
\hline Land Use & $12 \%$ \\
\hline
\end{tabular}

Due to their significant impact, the design and construction of buildings is critical to the success of a community. Through careful design and planning, communities have the ability to reduce the negative effects and increase the benefits that buildings provide. This is even more pronounced in regions where significant infrastructure or industry has not yet been developed. The model proposed in this paper outlines a process by which a community can capitalize on the design and construction of buildings to increase the economic, environmental, and social value within the community. Six steps for implementing building-centred community development strategies have been developed through experimentation and experience by the American Indian Housing Initiative program, and are now being tested:

Process for Building-Centred Community Development

Step 1: Identify inherent value within a community.

Step 2: Develop community-specific building technologies based sustainable use of community capital. 
Step 3: Design a prototype building that includes community-specific building technologies.

Step 4: Construct a prototype building and document and test its performance.

Step 5: Apply appropriate community-specific building technologies to existing and new buildings within the community

Step 6: Develop industries to support the installation, maintenance, and use of community-specific building technologies.

To evaluate the effectiveness of this process, two prototype homes, MorningStar Pennsylvania and MorningStar Montana, will be constructed in 2007 as a part of the Pennsylvania State University's Solar Decathlon Project and American Indian Housing Initiative Program, respectively. The MorningStar concept is designed to be a prototype home for a specific community that can serve as a catalyst for a more widespread implementation of sustainable design and practices. Each MorningStar homes will serve as residence, research laboratory, and educational outreach centre. Examples from the prototypes will be used to illustrate some of the technologies that are being developed.

\subsection{Identifying value}

For a given community, which in this case is defined as a system bounded by a geographical area, there are numerous sources of accessible value. In addition to economic wealth, there are also natural and social sources of value. A holistic analysis of sources of value within a community is similar to the study of ecology, which is considers the energy, material, and information flows through and within an ecosystem. In this paper, the value of these flows will be classified in terms of four different types of capital:

1) Environmental capital is the value of the natural resources and energy flows that exist within or pass through the community. Environmental capital can be classified as either renewable or non-renewable. Renewable environmental capital consists of resources and energy that are capable of being replaced in short term natural ecological cycles, such as solar radiation, wind, grasses, and fast growing trees. Non-renewable capital can be subdivided into that which is reusable such as water, stone, brick, or metal, and that which is not reusable such as fuel.

2) Economic capital consists of financial resources. Traditionally only economic capital has been the measure of growth and success of a community.

3) Social capital includes the skills, knowledge, shared values, trust, wellbeing and other capabilities of the people within a community. Social capital is difficult to measure but it includes many of the factors that determine the potential productivity and resulting value that can be generated within a community. 
4) Physical Capital is considered to be any non-human asset built by people. This includes buildings, infrastructure, and other products.

Assigning value to a resource can be a complex analysis due to the conflicting and synergistic relationships and the resulting effects. For example, a grove of trees performs many functions for a community and can be a source of multiple types of capital. The trees provide shade, flood control, protection from wind, habitats for other species, storm water management, a recreational area, and the potential for lumber. Depending on the development strategy selected, this resource can be utilized to create a net increase or decrease in the total capital of a community. When harvested sustainably, enough trees exist to properly serve all of their original functions but additional economic or physical capital can be generated through production of lumber. If not harvested sustainably, despite an increase the short-term economic or physical capital due to lumber production, the total capital will be reduced. This reduction stems from the need to find other means of providing storm water management, shade, habitat, recreational areas, wind protection, and a future substitute for local lumber. Alternately, if no other means are provided, there is the cost associated with the loss of those resources that will manifest itself through flood damage, higher building energy usage in winter and summer, and reduction of local biodiversity.

The potential benefits of buildings within a community have been greatly underutilized. Building construction should be a stimulant for growth with the community by creating businesses and jobs and developing skills. Operation and maintenance should not require continual energy and resources that could be better served for other purposes. In addition, buildings should serve as a source of social and cultural wealth by providing needed services and a creating a sense of "place" and pride for the community.

\subsection{Development of building technologies}

Once sources of value within the community have been identified, strategies need to be developed to grow the net capital. One such strategy is the development of community-specific building technologies. These may include both high-tech solutions and low-tech solutions that result from responsive and well-designed architecture. Thoughtful development of these building technologies can result in a net increase in the total capital of a community. Five approaches for developing community-specific building technologies are described in the following sections.

\subsubsection{Local materials}

Material costs for building construction account for roughly $40 \%$ of the total project cost. By replacing imported materials (i.e. from other communities) with local materials, a community can build their physical capital and retain more of their economic capital by keeping it within the community. Rapidly renewable materials that are extracted, manufactured, and assembled locally such as straw bales result in the greatest net increase in overall community capital. Prudent use of non-renewable but reusable materials, such as stone, can also result in an 
increase in net capital even though it transfers environmental capital into physical capital. Materials that are only partially manufactured locally, such as structurally insulated panels (SIPs), also have the ability to increase capital. The caveat with this subset is that communities must focus on processes that add the most value to the end product. For example SIPs consist of expanded polystyrene (EPS) with oriented strand board (OSB) adhered to either side to make the full wall or roof panel. The panels are then custom cut and detailed into prefabricated panels to meet the requirements of a project. The majority of the value is added by adhering the OSB to the EPS and customizing the panel which could easily be done locally, as opposed to complete production of the OSB and EPS which requires specialized facilities.

Although trade with other communities is meant to relieve local constraints, it also reduces the direct incentive for regions to maintain their environmental capital, such as in the case of importation of food and the resulting decreased need for local agricultural land [11]. Conversely, self-reliance requires that communities and their members be much more aware of the status and value of their environmental capital since consequences of their behaviour are quickly and completely visible at the local level [12]. By focusing on developing the most feasible industries first and trading for other materials, building-centred community development attempts to strike a balance between self-reliance and trade dependence.

The designs of the MorningStar prototypes are based on locally salvaged, produced, or purchased materials. The Montana home uses primarily straw bale and locally manufactured SIPs for the walls and roof. Similarly, the Pennsylvania home design utilizes reclaimed slate and sustainably harvested wood siding and for the cladding and SIPs and steel from local fabricators for the structure.

\subsubsection{Local renewable energy and water flows}

One of the most substantial costs to building owners over the life of the buildings is the cost of energy and water required for daily operations. Buildings or communities that are capable of producing their own energy from renewable sources are able to utilize previously unrealized environmental capital. In the case of solar power, there is more solar energy incident upon the earth in one hour that the entire world uses in a year [13]. By analyzing the natural energy flows within a community and the energy needs of a community, appropriate technologies can be selected to transform natural flows into useful energy. By doing so, less economic capital is needed to maintain and operate buildings and any production of excess energy can be used for vehicles or exported to create additional economic capital.

The MorningStar prototypes will make use of three sources of renewable energy: solar, wind, and geothermal. For Montana, where sunny days are plentiful, solar power will be used to create electricity and to heat domestic hot water. The Pennsylvania site has many overcast days but various photovoltaic and solar thermal technologies will be included to analyze the cost-benefit ratio for them in this region. In addition, the Pennsylvania home will also use wind 
power for additional electricity and a geothermal heat pump for heating. Another feature of the MorningStar Pennsylvania is future research plans to use excess energy produced by the home to fuel an electric or fuel cell vehicle to use renewable energy to also offset vehicle energy cost. Both prototypes will utilize rainwater catchment systems to reduce the need for potable water for low-grade domestic uses such as toilets, irrigation, and cleaning of public space.

\subsubsection{Climate responsive design}

Another means of reducing the lifecycle costs of a building is to develop designs that are considerate of the regional climate a thereby reduce energy, potable water, and maintenance needs. This approach makes use of previously unrealized physical capital to reduce the economic capital required to operate buildings. Climate responsive design also provides the opportunity to develop distinctive architectural styles that can add to the social capital of a community. By making use of durable materials, passive solar design, natural lighting strategies, and natural ventilation, buildings require less energy, water, and maintenance while still providing the same value to the community. This counters the modern trend in design to make use of technology which requires greater initial and long term investment, such as air conditioning, instead of architectural responses to regional climates [5].

Both prototypes homes make use of shading devices that control solar heat gain, natural lighting so that no electric lights are required during the day, and window placement to facilitate natural ventilation. For the Pennsylvania home, design focused on super-insulated wall and roof systems to minimize heat gain and loss throughout the year and a radiant heated stone flooring system was used to provide the most efficient distribution of heat. In Montana, the building walls will be constructed of straw bales with exterior and interior cement plaster. This system combines the benefits of insulation and thermal mass to provide a wall system that greatly reduces energy loss and moderates the extreme diurnal temperature fluctuations that occur in this region.

\subsubsection{Unskilled volunteer labour}

Labour is another substantial cost of construction accounting for roughly $40 \%$ of the total project cost depending on the complexity of the project. With the exception of the highly technical systems, such as controls, HVAC, plumbing, and electric, the majority of the construction does not require highly skilled labour. By considering constructability during the design process, buildings can be designed to so that there is a distinct separation between construction that requires skilled labour and that which can be performed by unskilled volunteer labour. Areas requiring skilled labour can be consolidated into modules and prefabricated off-site by professionals. Prefabrication allows for lower costs, improved quality, steady employment for workers, and incentive for greater training of the workforce [14]. The remainder of the building can be built by unskilled volunteer labour which can provide significant cost savings to the project. These complimentary strategies of focused technical systems into prefabricated modules and maximizing volunteer or unskilled involvement, 
allow physical capital to be grown within the community with minimal loss of economic capital. This approach also adds to the social capital by building community relationships and affording the opportunity for unskilled workers to develop basic construction skills and skilled workers to focus on improving their skills.

For both the MorningStar Montana and Pennsylvania, the technical systems (i.e. kitchen, bathroom, and mechanical spaces) are consolidated into a compact technical core that can be prefabricated, delivered to the site, and the remainder of the home built around it by volunteer or unskilled labour. The construction of both homes will be performed mostly by students from various universities and community volunteers that want to gain construction experience. Both homes are designed so that they can be constructed with conventional tools and with minimal use of heavy machinery.

\subsubsection{Local labour}

The use of local labour, both for unskilled and skilled work, allows for the economic capital needed for construction to stay within the community. Other than the cost for materials that are not available within the community, the remainder of cost for construction is retained by community as investments into construction related business, worker wages, technical expertise, and the actual buildings and the services that it will provide. In this way, economic capital within the entire community is mostly preserved and physical and social capital is increased. Another benefit to this approach is the growth of social capital through community involvement, the resulting relationships, and a sense of pride associated with creating a physical part of the community.

For both prototypes, almost all of the materials will be purchased from local businesses. Most of the highly technical systems used in the Pennsylvania home showcase new technologies being developed by researchers at Penn State or local businesses and has served as a stimulus for future research and business partnerships. These include a prognostic building controls system, solar thermal and advanced glazing technologies, and the rainwater catchment system. In Montana, the skilled labour is contracted to individuals in the community. These projects provide local workers opportunities for employment that otherwise would not exist.

\subsection{Application to the community}

Implementing these approaches throughout a community allows a distinctive architectural style and development pattern to emerge that reflects a greater understanding of how a community can conserve and generate value. Rather than running these analyses for each building, the building-centred community development process focuses on the development of a prototype building. Although more costly and requiring more time to develop, a prototype allows for the extra cost and effort to be limited to one building. Once the building technologies have been developed for the prototype, it is easier and more cost effective to apply them to additional buildings. The prototype can also serve as a 
long-term testing facility and outreach centre to provide cost-benefit analyses, local supplier contact information, installation process information, and performance metrics. This information can help policy makers and individuals decide which features are best suited for a given community and evaluate the feasibility of implementing these features into new and existing buildings.

The potential effects of widespread implementation of the building technologies featured in the prototype design also need to be considered. The economic analyses should consider the energy and materials use, job production, skill development, industry development, community development, and potential financing. The social analyses should consider the community's values, goals, building needs, skill or industry development needs, and dissemination of information.

\section{Conclusion}

The limitations of traditional community development are evident when observing the social pathologies that exist in many developed areas. Much of this is thought to be due to an emphasis on economic growth alone. By embracing more holistic strategies, community development can facilitate healthier and more sustainable growth. As a significant component of a community, the design and construction of buildings provide an opportunity to affect positive growth within a community. The proposed model for implementation of building-centred community development focuses on understanding and identifying of value within a community by considering its environmental, economic, physical, and social capital. Once these sources of value are realized, communities need to modify their policies and develop the best means to grow their capital. By developing and synthesizing buildingrelated strategies into a prototype, it can serve as a model for how these building technologies and ideas can be implemented throughout the community and development of related industries. By focusing on long-term sustainable growth of economic, environmental, and social capital within a community, the overall quality of life can be improved for present and future generations.

\section{References}

[1] Molotch, H., The City as a Growth Machine: Toward a Political Economy of Place. American Journal of Sociology 82(2): pp. 309-332, 1976.

[2] United Nations, Our Common Future: Report of the World Commission on the Environment and Development. New York, NY, United Nations, 1987.

[3] United Nations World Summit on Sustainable Development, Johannesburg Declaration on Sustainable Development. Johannesburg, South Africa, 2002.

[4] United Nations Conference on Environment and Development (Earth Summit), Agenda 21, Rio de Janeiro, Brazil, 1992.

[5] Leccese, M., Charter of the New Urbanism, McGraw-Hill, 2000. 
[6] About Smart Growth, Sustainable Communities Network Online. www.smartgrowth.org

[7] Hall, K. B., Community by Design: New Urbanism for Suburbs and Small Communities, McGraw-Hill, 2001.

[8] Whole Building Design Guide: The Role of Buildings and the Case for Whole Building Design. National Institute of Buildings Sciences Online. www.wbdg.org/wbdg_approach.php

[9] 1998-2005 GDP by Industry. Bureau of Economic Analysis. U.S. Dept. of Commerce online. www.bea.gov/bea/gdpbyind_data.htm

[10] Levin, H., Systematic Evaluation and Assessment of Building Environmental Performance (SEABEP). Conference on Buildings and Environment, Paris 1997.

[11] Rees, W. E., Wackernagel, Mathis, Ecological Footprints and Appropriated Carrying Capacity: Measuring the Natural Capital Requirements of the Human Economy. Investing in Natural Capital: The Ecological economics Approach to Sustainability, Stockholm, Sweden, Island Press, pp. 362-390, 1994.

[12] Dryzek, J., Rational Ecology: Environmental and Political Economy. Basil Blackwell, New York, 1987.

[13] Fast Solar Energy Facts, Solarbuzz Online. www.solarbuzz.com/ FastFactsIndustry.htm

[14] Gorgolewski, M. T., The Potential for Prefabrication in UK Housing to Improve Sustainability. Smart and Sustainable Built Environment, eds. J. Yan, P.S. Brandon, and A.C. Sidwell, Blackwell Publishing Ltd., Malden, MA 2005. 